\title{
Editorial Gatekeepers Confronted by the Electronic Journal
}

\section{Ronald F. Dow}

\begin{abstract}
Refereed journals perform a crucial role in the formal dissemination of new knowledge. Significant to the communication process are editors and editorial board gatekeepers. These gatekeepers were surveyed to learn their views on supplanting paper-formatted journals with journals in electronic formats. The survey showed that editorial gatekeepers, although generally supportive of the creation of electronic journals, are still very enamored of the paper format as both a means of publishing and a medium for archiving academic writing. It is suggested that editorial gatekeepers may view electronic journals as an extension of the informal communication system of the disciplines rather than as a medium for supplanting the traditional paper format of academic journals.
\end{abstract}

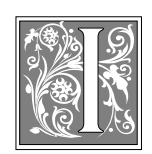

ntegral to the scholarly endeavor is the discovery and formal communication of new knowledge. The paper journal has served as the primary medium of formal academic communication since the seventeenth century. At the close of the nineteenth century, as the academic disciplines became more structured and academic occupations became professionalized, acceptance for publication in an academic journal assumed an honorific aspect. ${ }^{1}$ The individuals who control the relationship between academic producers of ideas and their audience of readers and between academic obscurity and the professional recognition earned by those who publish are the editors and referees of academic journals. ${ }^{2}$

In a seminal paper on gatekeeping, Kurt Lewin described a gatekeeper as an individual or group empowered to make the decision of "in" or "out." 3 Decisions are partly predicated on ideology - that is, a system of values and beliefs that determines what the gatekeeper considers to be "good" or "bad" — and partly based on the way the gatekeeper perceives a particular situation. A similarity exists between Lewin's discussion of

The paper journal has served as the primary medium of formal academic communication since the seventeenth century.

gatekeepers and the role that editors and referees perform in academic publishing. For example, Richard D. Whitley identified a relatively high degree of personalization in the formal communication system in British social sciences. ${ }^{4}$ Individual editors often operated independently of one another, tended to ignore the operation of other journals in the academic spe-

Ronald F. Dow is Dean of the River Campus Libraries at the University of Rochester; e-mail: Rond@rcl.lib.rochester.edu. 
cialization, and frequently relied on personal knowledge of immediate colleagues when evaluating manuscripts. Similarly, in a study of the gatekeeper role in educational journal publishing, Robert .J. Silverman and Erik L. Collins concluded, from an extensive survey of participants in the publication process, that editors assumed the decision-making role in scholarly and research journal publishing by using a combination of their own judgment and the advice of reviewers when determining which manuscripts to let in and which ones to keep out. ${ }^{5}$

Editorial gatekeepers are empowered to control the quality of the journal by determining what ideas are let "in" and which ones are kept "out." By their decisions, the gatekeepers facilitate the awarding of status to professionals working within the discipline, maintain the intellectual boundaries of the discipline, and serve the advancement of the academic discipline as an organization of professionals. ${ }^{6}$ The outcome of their decisions appears as literature in paperformatted scholarly and research journals. As a consequence, journal editors and referees assume a significant gatekeeper role within their disciplines and their academic professions. ${ }^{7}$

In recent years, a number of initiatives have sought to advance the creation of electronically formatted journals and to forward this publication medium as a replacement for the traditional paper-formatted research journal. From the works cited above, editors, with the assistance of editorial reviewers, are important decision makers and even gatekeepers within the context of formal academic publishing. The opinion that these editorial gatekeepers hold toward the development of e-journals and their perspective on supplanting paper-formatted journals with e-journals may be important when assessing the fate of journal publishing formats. Therefore, a survey was undertaken to determine editorial gatekeeper attitudes toward a transition of paper-formatted journals to an electronic medium.

\section{The Study}

The purpose of this study was to determine whether editorial gatekeeper attitudes might obstruct or assist the transition of paper-formatted academic journals to electronic formats. To ascertain gatekeeper attitudes, a survey of gatekeepers in academic journal publishing was undertaken. The term attitude has been defined, for the purposes of measurement, as a state of readiness or tendency to respond in a certain manner when the object of the attitude is stimulated. ${ }^{8}$ Attitudes, reinforced by personal beliefs and feelings, may precipitate or account for some future action. Assuming that such is the case, gatekeeper attitudes toward the ongoing role of journals may account for gatekeeper actions relative to the transition of paper-formatted journals to electronic formats.

A population of editors and editorial board members in six disciplines, listed below by discipline and journal, were targeted for this study:

- Mechanical Engineering: Journal of Applied Mechanics and Journal of Fluid Mechanics

- Botany: American Journal of Botany and International Journal of Plant Sciences

- Agricultural Economics: Agribusiness and American Journal of Agricultural Economics

- Anthropology: American Anthropologist and Cultural Anthropology

- Educational Administration: Educational Administration Quarterly and Journal of Educational Administration

- Political Science: American Political Science Review and Political Science Quarterly

The titles chosen are the more prominent publications in a number of disciplines that fall along a continuum based on paradigm strength of the discipline. ${ }^{9}$ These titles were selected to improve the likelihood that editors and editorial board members associated with the journals would be academic leaders within their disciplines. Neither these journals nor their editorial board members can be viewed statistically as representative of other jour- 
nals or editors, in these or other disciplines. However, there also is no reason to believe that their views would not reflect the views of editors and editorial board members of similar journals in other disciplines. It is equally conceivable that editors and board members of smaller or less traditional or more specialized journals might express different attitudes from those expressed by these gatekeepers.

The total number of people surveyed was determined by the actual list of names identified on the journal's title page as being on the editorial board or in an editorship position. Excluded from the survey were editors and editorial board members not affiliated with colleges or universities or whose institutional addresses were outside North America.

The survey instrument was designed to measure respondent answers to a series of statements relevant to the study. A Likertlike scale was chosen to transmit responses because it allowed subjects to place themselves on an attitude continuum ranging from "strongly agree" to "strongly disagree" for each statement asked.

From the outset, it was recognized that without extensive pretesting of the survey instrument, involving numbers greater than the ultimate population to be surveyed, it would be impossible to validate the degree of measurement achieved by the survey instrument. In short, it was very likely that the various modifiers differentiating among the alternative responses on the survey instrument ("strongly agree," "agree," "disagree," and "strongly disagree") would have different levels of meaning for each respondent. The primary procedure for improving scalability in such cases is the combining of categories. For this study, cases "strongly agree" and "agree" were combined as were "disagree" and "strongly disagree" when the surveys were scored and the results tabulated. ${ }^{10}$

The scores produced ordinal values. The frequency of each value was tabulated by response and the medians were calculated. Cross-tabulations of statements compared percentages of responses, and a correlation between values was calculated using Kendall's tau. Kendall's tau is a measure of the extent to which one respondent's rankings on one variable are associated with his or her rankings of a second variable when the rankings are collected through categories of responses, as was done in this study. Kendall's rank correlation between ordinal variables is identical to Pearson's rho in that the computed coefficient varies between -1 and +1 , providing information on the strength and direction of relationships between variables. Kendall's tau, although producing slightly lower correlation coefficients than rho, is preferred here because it was suspected that a large proportion of individuals surveyed would have tied ranks on many of the same variables. ${ }^{11,12}$

\section{The Survey}

In early 1997, 223 surveys were mailed to the targeted population of editors and

\section{TABLE 1}

\section{Survey Characterized by Discipline}

\begin{tabular}{lccc}
\hline \hline Discipline & No. Targeted & No. Responding & \% Responding \\
\hline Mechanical engineering & 15 & 5 & 33 \\
Botany & 31 & 19 & 61 \\
Anthropology & 50 & 25 & 50 \\
Agricultural economics & 32 & 19 & 59 \\
Political science & 51 & 32 & 63 \\
Educational administration & 44 & 29 & 66 \\
\hline \multicolumn{1}{c}{ Total } & 223 & 129 & \\
\hline
\end{tabular}


editorial board members. The names of the targeted population were culled from the title pages of current issues of the journals to be surveyed. Every effort was made to identify specific campus addresses for each faculty surveyed. Campus directories available over the Internet were canvassed, and "who's who"-type guides and association membership rosters were consulted to make the mailing as specific by local address as possible. A reminder was sent to nonrespondents thirty days after the initial mailing.

A total of 129 usable survey instruments was returned for a response rate of 58 percent. Table 1 characterizes the population surveyed by discipline, indicating the number of editors and editorial board members that were targeted with questionnaires and the count and percentage of respondents. The respondents were associated with seventy-three different American colleges and universities.

The research question focused on gatekeeper attitudes toward creating ejournals and supplanting the paper-format with an electronic format. To address the question, gatekeepers first were asked whether they favored the development of e-journals (see table 2). Overall, 58.6 percent of respondents supported the development of e-journals, compared to 14.1 percent who did not support their development.

A series of follow-up statements was offered to better understand why respondents who supported the development of e-journals did so. Gatekeepers were asked

\section{TABLE 3}

If refereed journals were available in electronic format, it would be easier to find articles or subsections of articles to support teaching and research $(\mathrm{N}=129)$.

\begin{tabular}{llll} 
Agreed & Disagreed & Uncertain & Median \\
\hline $48.4 \%$ & $30.5 \%$ & $21.1 \%$ & Agree \\
{$[62]$} & {$[39]$} & {$[27]$} & \\
\hline
\end{tabular}

whether the use of refereed journals in electronic formats would make it easier to find articles or subsections of articles to support teaching and research. The belief that electronic formats enhance access to the research literature is one of the most frequently cited positive values associated with the development of e-journals. Table 3 shows how gatekeepers responded to this statement. Slightly fewer than half of respondents agreed with the statement. When responses were correlated with gatekeepers who indicated they supported the development of e-journals, a Kendall's tau value of .261 was produced, indicating that a positive correlation between the two statements existed. Of those who favored e-journal development, 70.5 percent agreed that ease in finding literature would improve with electronic formats. Responses by those who opposed the development of e-journals were more broadly distributed: 41.4 percent agreed that it would be easier to use the literature, 37.9 percent disagreed, and 20.7 percent were uncertain.

A possible explanation for the variance between those who supported e-journal development and those who did not could relate to respondents' overall attitudes about the vastness of the literature of the discipline. Proponents of electronic publishing maintain these formats provide easier access to the growing vastness of the literature of the disciplines. Gatekeepers who believed that the literature of their discipline had become too vast might have supported the development of e-journals because they saw electronic formats as addressing the problem of accessing a growing mass of material. On the other hand, those 
TABLE 4

Gatekeepers Favoring the Development of Electronic Journals by Discipline

\begin{tabular}{lrcr} 
Discipline & Favored & Did not favor & Uncertain \\
\hline Botany & $47.4 \%$ & $26.3 \%$ & $26.3 \%$ \\
Mechanical engineering & $60.0 \%$ & $40.0 \%$ & $0.0 \%$ \\
Agricultural economics & $68.4 \%$ & $21.1 \%$ & $10.5 \%$ \\
Anthropology & $68.0 \%$ & $24.0 \%$ & $8.0 \%$ \\
Educational administration & $65.5 \%$ & $27.6 \%$ & $6.9 \%$ \\
Political science & $45.2 \%$ & $32.3 \%$ & $22.6 \%$ \\
\hline
\end{tabular}

who disagreed that the literature had become too vast might have been less supportive of electronic formats because they did not see the new format as solving a problem.

Gatekeepers were asked whether the literature important to their discipline had become too vast for many in the discipline to manage. Just over 63 percent of all respondents agreed that it had. The correlation between vastness of literature and both the capabilities of e-journals to improve use and access to the literature and support for e-journal development produced Kendall's tau values of .033 and .046 , respectively. The low correlation values indicate that support for the development of e-journals does not appear to have arisen out of a shared belief that e-formats solve problems with the growing vastness of a specific discipline's research literature.

Researchers have found diversity by academic discipline in faculty orientation and productivity. Disciplinary cultures can vary greatly to a degree that can account for differences of gatekeeper perspective about the future of paper-formatted journals. It was speculated that attitudes of editors and editorial board members could vary based on the discipline of the respondent, explaining some of the variance in attitude toward e-journal development. Gatekeeper attitudes toward e-journal development were correlated by respondents' academic discipline. The correlation produced a Kendall's tau value of -.111, indicating a slightly negative correlation between the respondent's discipline and his or her attitude toward e-journal development. As table 4 shows, little of the variance between those supporting and those not supporting the development of e-journals can be accounted for by discipline. What does seem clear is that respondents, although from a continuum of disciplines based on paradigm strength, reflected shared attitudes on the subject of the creation of e-journals.

Another possible explanation of variance among those who supported the development of e-journals, those who did not, and those who were uncertain may be predicated on the respondents' previous experience with journals in electronic formats. Gatekeepers were asked if they had ever used e-journals. Of those responding, 65.1 percent reported never having used a journal in an electronic format. The correlation between those who supported e-journal development and previous experience with electronic journals produced a Kendall's tau value of .171, indicating a slightly positive correlation between the two statements. Although somewhat significant, such a low correlation indicates that previous experience with ejournals was a not a driving factor in understanding gatekeeper responses to the development of e-journals.

Gatekeepers were asked whether they had ever formally participated in discussions about e-journals. Overall, 38.6 percent of respondents had participated in such discussions and 36 percent of those favoring development of e-journals had done so. Interestingly, 61.1 percent of those not favoring the development of ejournals had participated in formal dis- 


\begin{tabular}{|c|c|c|c|}
\hline \multicolumn{4}{|c|}{$\begin{array}{c}\text { TABLE } 5 \\
\text { Of those supporting the development of } \\
\text { electronic journals, at least into the near } \\
\text { future, for an electronic journal in the } \\
\text { discipline to be important, it must be } \\
\text { archived in paper format }(\mathrm{N}=129) \text {. } \\
\end{array}$} \\
\hline Agreed & Disagreed & Uncertain & Median \\
\hline $\begin{array}{l}80 \% \\
{[60]}\end{array}$ & $\begin{array}{l}13.7 \% \\
{[10]}\end{array}$ & $\begin{array}{l}6.7 \% \\
{[5]}\end{array}$ & Agree \\
\hline
\end{tabular}

of support for e-journal development. Only editorial board members who supported the development of e-journals were asked whether, at least in the near future, electronic journals in the discipline would need to be archived in paper format in order to be considered important (see table 5). Those who disagreed with the development of ejournals were asked to respond to the same statement (see table 6). Responses from the group who were uncertain cussions about electronic formats at professional meetings, in editorial broad meetings, or on campus. It is possible to speculate that those not favoring the development of e-journals are either more willing to articulate their point of view or are more frequently asked to participate in discussions on this topic.

Overall, 58.6 percent of respondents favored the development of electronic journals. A significant percentage of gatekeepers who supported e-journal development agreed that the format would improve access to the content of journals, and almost half of the respondents who indicated that they did not support e-journal development also concluded that the electronic format would improve access to the literature of their discipline. Based on the survey, no strong relationship appears to exist between respondents' support for the development of e-journals and their discipline, previous experience with e-journals, or sense of the vastness of the literature of the discipline.

\section{Attitudes Toward the Paper Format of the Journal}

The journal is the key element of the formal publication system in academia. A characteristic of formal publication has been that published information is permanently archived. To determine whether issues related to the paper archiving of e-journals, or the desire to publish e-journals in parallel with paper editions, could explain why some gatekeepers supported the development of e-journals, respondents were categorized by level about the need for paper archiving of e-journals similarly reported, with 88.6 percent agreement, that archiving in paper would be important.

Respondents who indicated support for e-journal development were then asked whether e-journals needed to be published in both paper and electronic formats (see table 7). Those not supporting e-journal development were similarly asked if they thought e-journals needed to be published in both paper and in electronic formats (see table 8).

A significant percentage of those not supporting the creation of e-journals agreed that, if developed, e-journals would need to be published with a paper equivalent.

Statements supporting the paper archiving of e-journals and the parallel publishing of e-journals in paper formats were equally supported by those gatekeepers who agreed with the development of e-journals and those who did not agree or were uncertain as to their position. Only four respondents (3\% of the total) agreed that neither paper print-

\begin{tabular}{|c|c|c|c|}
\hline \multicolumn{4}{|c|}{$\begin{array}{l}\text { TABLE } 6 \\
\text { Of those not supporting the develop- } \\
\text { ment of electronic journals, at least into } \\
\text { the near future, for an electronic journal } \\
\text { in the discipline to be important, it must } \\
\text { be archived in paper format }(\mathrm{N}=129) \text {. }\end{array}$} \\
\hline Agreed & Disagreed & Uncertain & Median \\
\hline $\begin{array}{l}94.4 \% \\
{[17]}\end{array}$ & $\begin{array}{l}0 \% \\
{[0]}\end{array}$ & $\begin{array}{l}5.6 \% \\
{[1]}\end{array}$ & Agree \\
\hline
\end{tabular}


ing nor archiving of journals was important in an environment of e-journal publishing. Another three respondents $(2 \%)$ were equally uncertain that paper was not required somewhere in the publishing process, either in the format of the journal or as a device for archiving.

Academic communication takes two forms: the presentation of papers and discussion of research results, and the publication of the same in professional journals. ${ }^{13}$ The delivering of papers, the distribution of preprints, and the face-to-face discussion of research results that occur at professional meetings define the informal communication system. ${ }^{14,15}$ The informal communication system provides the researcher great freedom in the selection of both the media and the audience addressed. It allows all work that reaches even minimum scientific standards to be disseminated, even though that work may be unfinished or its claims unsubstantiated. The information conveyed is commonly abstracted, usually colloquial, frequently incomplete, and often vague. The results may even turn out to be false. Equally important, the information is often archived only temporarily and, ultimately, is difficult to retrieve. Indeed, an author is likely to have disseminated his or her manuscript through the informal communication system prior to submitting it to a journal for publication for the purpose of obtaining feedback on his or her findings and interpretations from relatively friendly audiences. ${ }^{16}$ Meetings organized by professional associations are excellent forums

\begin{tabular}{|c|c|c|c|}
\hline \multicolumn{4}{|c|}{$\begin{array}{l}\text { TABLE } 8 \\
\text { Of those not supporting the } \\
\text { development of electronic journals, } \\
\text { an electronic journal, to be successful, } \\
\text { also must be published in paper format } \\
(\mathrm{N}=129) \text {. }\end{array}$} \\
\hline Agreed & Disagreed & Uncertain & Median \\
\hline $88.9 \%$ & $5.6 \%$ & $5.6 \%$ & Agree \\
\hline
\end{tabular}

for informal communication with members and the intellectual leaders of the discipline, while excluding nonmembers from the dialogue.

The surveyed gatekeepers served on the editorial boards of the most prestigious journals within their disciplines; thus, it would seem unlikely that these scholars would choose to publish the results of their research in anything other than a journal with a reputation for the highest quality. Yet, when asked whether they would publish in an e-journal, only 19.7 percent of the gatekeeper respondents believed they would not do so at some point in their careers (see table 9). Because it is counterintuitive to believe that gatekeepers would publish research results in journals that were other than of the highest quality or reputation, the data support the supposition that gatekeepers did not consider e-journals as replacements for the paper-formatted publications that make up the formal communication mechanism of the disciplines. However, it is perfectly conceivable that gatekeepers would continue to explore all aspects of the informal communication mechanisms of the discipline to test research results. That could explain why so many gatekeepers agreed, or at least were uncertain as to their willingness, to publish in an e-journal that would be of the informal communication mechanism of the disciplines and why only forty-one respondents $(32.3 \%)$ wished to see their own journal available in electronic format.

Gatekeepers also were asked whether they thought e-journals were 
a publishing fad (see table 10). When responses to this statement were correlated with the responses to the statement asking whether the gatekeeper supported e-journal development, a Kendall's tau value of .526 was produced, indicating a strong correlation between the two statements. In reviewing the correlation, those who supported e-journal development strongly disagreed that ejournal publishing was a fad and those who disagreed with e-journal development strongly agreed that it was a fad $(38.9 \%)$, although responses also were distributed in other categories $(33.3 \%$ were uncertain and $27.8 \%$ disagreed). Again, those who were uncertain of their support for the development of e-journals were just as uncertain about whether ejournals were a fad $(57.1 \%$, compared to $5.7 \%$ who believed they were a fad).

\section{Conclusion}

It has been maintained that editors and referees of academic journals perform a gatekeeper function for their disciplines and their professions. The mechanism they use for making "in" or "out" decisions is publication in refereed academic or scholarly journals. It would appear important to understand the attitudes that gatekeepers have toward the device that is their mechanism of control because attitudes may precipitate or account for

\begin{tabular}{|c|c|c|c|}
\hline \multicolumn{4}{|c|}{$\begin{array}{c}\text { TABLE } 10 \\
\text { The electronic journal is just another } \\
\text { publishing fad }(\mathrm{N}=128) \text {. }\end{array}$} \\
\hline Agreed & Disagreed & Uncertain & Median \\
\hline $\begin{array}{l}7.8 \% \\
{[10]}\end{array}$ & $\begin{array}{l}64.1 \% \\
{[82]}\end{array}$ & $\begin{array}{l}28.1 \% \\
{[36]}\end{array}$ & Disagree \\
\hline
\end{tabular}

TABLE 9

At some point in my professional career, I will publish in an electronic journal (n=127).

\begin{tabular}{llll} 
Agreed & Disagreed & Uncertain & Median \\
\hline $38.6 \%$ & $19.7 \%$ & $41.7 \%$ & Uncertain \\
{$[49]$} & {$[25]$} & {$[53]$} &
\end{tabular}

some future action these stakeholders initiate. In this case, it would appear significant to understand editorial gatekeeper attitudes toward the paper format of the journal and toward proposed replacements to that medium in order to better overcome possible objections by gatekeepers to attempts at change.

This survey showed that editorial gatekeepers, although generally supportive of the creation of e-journals, are still very enamored of the paper format. One conclusion supported by the data is that many of the respondents see the e-journal as supportive of the informal communication processes of the discipline and not as a replacement for the paper-formatted journal, which is the backbone of the formal communication processes of the disciplines.

Change agents who are aware of gatekeeper attitudes may wish to affirm, when experimenting with the establishment of e-journals as devices for supplanting the paper-formatted journal, that their experiments are directed at the formal communication mechanisms of the discipline. Such an affirmation will force gatekeepers to view alternative mediums as affecting the social processes they control and, as a result, to begin to address the real hurdles to be overcome in successfully implementing an alternate format for the paper journal.

\section{Notes}

1. Talcott Parsons and Gerald M. Platt, The American University (Cambridge, Mass.: Harvard Univ. Pr., 1973), 112.

2. Lewis A. Coser, "Publishers As Gatekeepers of Ideas," Annals of the American Academy of Political and Social Sciences 421 (Sept. 1975): 14-31.

3. Kurt Lewin, "Psychological Ecology," in Field Theory in Social Science: Selected Theoretical 
Papers by Kurt Lewin, ed. D. Cartwright (New York: Harper \& Brothers, 1951), 170-87.

4. Richard D. Whitley, "The Formal Communication System of Science. A Study of the Organisation of British Social Science Journals," in The Sociology of Sociology, ed. P. Halmos (Keele, Staffordshire: Univ. of Keele, Sociological Review Monograph No. 16, 1970), 163-79.

5. Robert J. Silverman and Erik L Collins, The "Gatekeeper" Role in Educational Journal Publishing. Final Report (Washington, D.C.: National Institute of Education, 1975). ERIC Document Reproduction Service No.ED 111427.

6. Ronald F. Dow, "Gatekeeper Attitudes toward Supplanting Paper Journals with Electronic Alternatives" (Ph.D. diss, Pennsylvania State Univ., 1998).

7. Harriett Zuckerman and Robert K. Merton, "Patterns of Evaluation in Science: Institutionalization, Structure and Functions of the Referee System," Minerva 9 (Jan. 1971): 66-100.

8. Abraham N. Oppenheim, Questionnaire Design, Interviewing and Attitude Measurement (New York: Pinter Publishers, 1992), 174-95.

9. Anthony Biglan, "The Characteristics of Subject Matter in Different Academic Areas," Journal of Applied Psychology 57 (June 1973): 195-203.

10. Oppenheim, Questionnaire Design, Interviewing and Attitude Measurement.

11. Alan Agresti, Statistical Methods for the Social Sciences (San Francisco: Dellen Publishing, 1986), 219-20.

12. Alan Bryman and Duncan Cramer, Quantitative Data Analysis for Social Scientists (New York: Routledge, 1990), 173.

13. Talcott and Platt, The American University, 12.

14. William D. Garvey and Belver C. Griffith, "Scientific Communication: Its Role in the Conduct of Research and Creation of Knowledge," American Psychologist 26 (Apr. 1971): 359-60. 154.

15. William D. Garvey, Communication: The Essence of Science (New York: Pergamon Pr., 1979),

16. Garvey and Griffith, “Scientific Communication,” 358. 